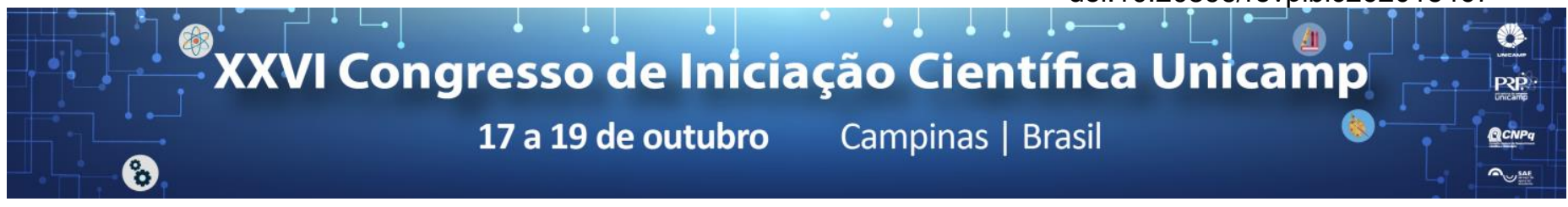

\title{
Remoção de Losartana Potássica em solução aquosa por argila organofílica comercial
}

\author{
Franco T. Sbragia*, Júlia R. de Andrade, Melissa G. A. Vieira, Meuris G. C. da Silva
}

\section{Resumo}

Este trabalho avaliou a adsorção do fármaco losartana potássica usando argila organofílica comercial Spectrogel - Tipo C. Avaliou-se a influência do $\mathrm{pH}$, seguido de estudo cinético da adsorção do fármaco em diferentes concentrações para determinar o tempo de equilíbrio e investigar os mecanismos do processo. Os dados experimentais foram ajustados aos modelos cinéticos de pseudoprimeira ordem, pseudossegunda ordem, Boyd e difusão intrapartícula.

\section{Palavras-chave:}

Adsorção, Losartana Potássica, Argila organofílica.

\section{Introdução}

A crescente detecção de fármacos no meio ambiente gera uma busca por métodos avançados eficazes de tratamento de água e efluentes. O processo de adsorção usando argila como adsorvente não convencional e de baixo custo é uma tecnologia extremamente promissora para a remoção de fármacos. ${ }^{1} \mathrm{O}$ objetivo deste trabalho é avaliar o potencial de adsorção do fármaco losartana potássica de solução aquosa usando uma argila organofílica comercial, Spectrogel® Tipo C.

\section{Resultados e Discussão}

Figura 1. Efeito do pH na quantidade adsorvida.

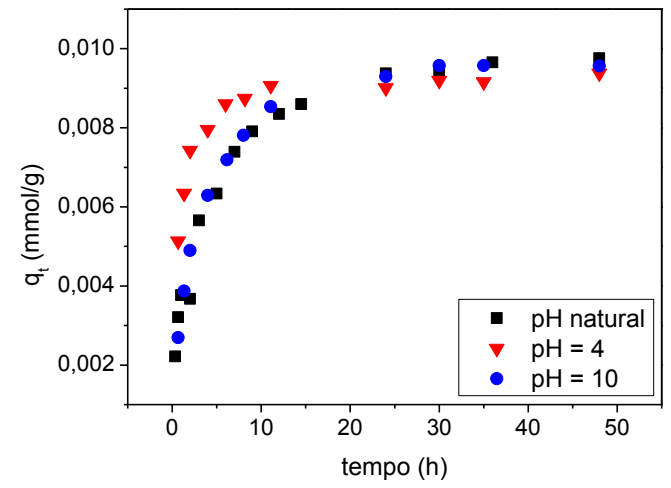

Figura 2. Curvas cinéticas adsorção de losartana.

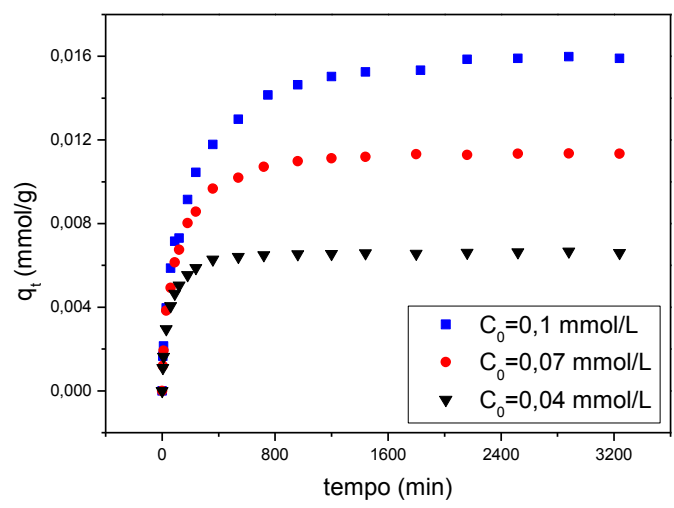

Conforme Figura 1, diferentes condições de $\mathrm{pH}$ ofereceram resultados similares de quantidade final adsorvida de losartana pela argila. Assim, as próximas etapas serão executadas sem controle de $\mathrm{pH}$.

A Figura 2 apresenta as curvas cinéticas de adsorção. Nota-se que quanto maior a concentração inicial de fármaco, maior a capacidade de adsorção, e que o equilíbrio é atingido após cerca de 1500 minutos.

A Tabela 1 exibe os parâmetros dos modelos matemáticos ajustados aos dados cinéticos. Tem-se que o modelo de pseudossegunda ordem oferece melhor ajuste que o de pseudoprimeira ordem (maior $\mathrm{R}^{2}$ e menor AICc), indicando a ocorrência de quimissorção. Sobre os mecanismos de difusão, o ajuste não satisfatório dos modelos de difusão intrapartícula e de Boyd indica a transferência de massa externa como etapa limitante do processo.

Tabela 1. Parâmetros dos modelos cinéticos de pseudoprimeira ordem (PFO), pseudossegunda ordem (PSO), Boyd e difusão intrapartícula (DIF).

\begin{tabular}{|c|c|c|c|c|}
\hline \multirow{2}{*}{ Modelo } & \multirow{2}{*}{ Parâmetro } & \multicolumn{3}{|c|}{ Concentração inicial (mmol/L) } \\
\hline & & 0,10 & 0,07 & 0,04 \\
\hline \multirow{4}{*}{ PFO } & $\mathrm{k}_{1}\left(\min ^{-1}\right)$ & 0,0056 & 0,0084 & 0,0158 \\
\hline & qe $(\mathrm{mmol} / \mathrm{g})$ & 0,0151 & 0,0110 & 0,0064 \\
\hline & $\mathrm{R}^{2}$ & 0,97 & 0,97 & 0,98 \\
\hline & $\mathrm{AICc}$ & $-271,57$ & $-289,71$ & 314,49 \\
\hline \multirow{4}{*}{ PSO } & $\mathrm{k}_{2}(\mathrm{~g} / \mathrm{mmol} / \mathrm{min})$ & 0,4731 & 1,0978 & 3,9791 \\
\hline & $\mathrm{qe}_{\mathrm{e}}(\mathrm{mmol} / \mathrm{g})$ & 0,0165 & 0,0117 & 0,0068 \\
\hline & $\mathrm{R}^{2}$ & 0,99 & 1,00 & 1,00 \\
\hline & $\mathrm{AICC}$ & $-299,00$ & $-323,80$ & 358,06 \\
\hline \multirow{3}{*}{ Boyd } & $B\left(\min ^{-1}\right)$ & 0,0018 & 0,0022 & 0,0016 \\
\hline & $\mathrm{Di}_{\mathrm{i}}\left(\mathrm{cm}^{2} / \mathrm{min}\right)$ & $\begin{array}{l}1,91 \mathrm{E}- \\
07\end{array}$ & $\begin{array}{l}2,41 \mathrm{E}- \\
07\end{array}$ & $\begin{array}{l}1,70 \mathrm{E}- \\
07\end{array}$ \\
\hline & $\mathrm{R}^{2}$ & 0,9575 & 0,9360 & 0,7409 \\
\hline \multirow{3}{*}{ DIF } & $\mathrm{ki}\left(\mathrm{mmol} / \mathrm{g} / \mathrm{min}^{0,5}\right)$ & 0,0001 & 0,0001 & 0,0031 \\
\hline & $\mathrm{C}(\mathrm{mmol} / \mathrm{g})$ & 0,0098 & 0,0080 & 0,0002 \\
\hline & $\mathrm{R}^{2}$ & 0,93 & 0,95 & 0,97 \\
\hline
\end{tabular}

\section{Conclusões}

Concluiu-se que o pH não tem influência significativa no processo de adsorção de losartana por argila Spectrogel. O tempo para atingir o equilíbrio é de cerca de1500 min e o ajuste satisfatório do modelo de pseudossegunda ordem indica a presença de quimissorção. Por fim, verificou-se a predominância da resistência externa à transferência de massa como etapa controladora.

\section{Agradecimentos}

À Purifarma e à Spectrochem pela doação do fármaco e da argila, respectivamente, e à CAPES, ao CNPq e à FAPESP [Proc. 2016/05007-1] pelo apoio financeiro.

${ }^{1}$ De Andrade, J. R.; Oliveira, M. F; Da Silva, M. G. C.; Vieira, M. G. Ind. Eng. Chem. Res. 2018, 57, 3103-3127. 